\title{
Contaminación del Río Jipijapa y sus efectos hacia el turismo del Cantón Jipijapa, Ecuador
}

\section{Contamination of the Jipijapa River and its effects to the tourism of the Village Jipijapa, Ecuador}

Ingrid Jahaira Sánchez Guaranda, Miguel Ángel Parrales Oviedo, Luis Manuel Toala Baque, Shyla Orlando Narváez

RESUMEN: La contaminación del río Jipijapa y sus efectos hacia el turismo del cantón Jipijapa afecta de manera notoria debido a la falta de la conservación, principalmente en el tramo que cruza por el centro de la ciudad el que debería dar una mejor apariencia. Con el trabajo de investigación se pretende crear conciencia en los habitantes del cantón y lograr su aporten a la recuperación del río motivando a las autoridades competentes que planifiquen las actividades turísticas posibles de ejecutar para fomentar el turismo y el desarrollo económico del cantón. Para realizar esta investigación se utilizó la observación directa, obtención de información primaria y secundaria, análisis de examen directo, cultivo bacteriano y cultivo micológico del agua, analizando la demanda teniendo como muestra 194 turistas que visitaron la ciudad, con un margen de error del 5\%; además se entrevistó a varios habitantes locales para saber lo que opinan sobre la necesidad de tomar medidas de prevención y disminuir la contaminación, con el objetivo de lograr una mejor imagen de un hermoso río, tanto para propios y extraños, llamando la atención del turista nacional, que buscaría conocerlo, para lo cual necesitará comida, hospedaje, transporte y actividades turísticas, con esto se aportaría al desarrollo económico y a la generación de fuente de trabajo, como también nuevos emprendimientos e ideas de negocios.

PALABRAS CLAVES: Contaminación; Problemas Ambientales; Río Jipijapa; Cantón Jipijapa. 


\section{ABSTRACT}

The pollution of the Jipijapa River and its effects on the tourism of the Jipijapa canton affects notoriously due to the lack of conservation of this, mainly in the section that crosses through the center of the city, which should give a better appearance. With this research work is intended to raise awareness in the inhabitants of the canton and achieve their contribution to the recovery of the river motivating the competent authorities to plan tourism activities possible to implement to promote tourism and economic development of the canton. To carry out this research, direct observation, obtaining primary and secondary information, analysis of direct examination, bacterial culture and mycological culture of water were used, analyzing the demand taking as sample 194 tourists that visited the city, with a margin of error of $5 \%$; also interviewed several local inhabitants to know what they think about the need to take preventive measures and reduce pollution, with the aim of achieving a better image of a beautiful river, both for own and strangers, calling the attention of the national tourist, who would seek to know him, for which he will need food, lodging, transport and tourist activities, with this would contribute to the economic development and the generation of work source, as well as new business ideas and ideas.

KEYWORDS: Pollution; Environmental Problems; Jipijapa River; Jipijapa Canton.

\section{Introducción}

La ciudad de Jipijapa está influenciada por la cuenca del río Jipijapa la cual abarca una superficie de 253,850 $\mathrm{Km}^{2}$ del cantón (Muñoz, 2015, pág. 80). Se encuentra a una altitud de $18 \mathrm{msnm}$, sus coordenadas son $1^{\circ} 19^{\prime} 60^{\prime \prime}$ $S$ y $80^{\circ} 45^{\prime} 0 " \mathrm{~W}$ en formato DMS y latitud: -1.33333 longitud: -80.75 (en grados decimales) (GETAMAP, 2017). Mediante mapeo en el programa Google Earth se determina que el río tiene una extensión de 33,64 kilómetros la cual nace desde el sitio Andil y desemboca en la playa de Puerto Cayo parroquia rural del cantón; durante el recorrido de los tramos del sector 5 de la ciudadela 3 de Mayo y en la calle Alajuela (ultima entrada) se pudo observar que la magnitud de la maleza hace que se obstaculice el cauce y tiende a disminuir la fluidez, luego en la avenida Universitaria hasta el puente de la escuela Daniel López se ve que hay basura que contamina el agua y la fluidez del río es poca, aparenta ser un estero mas no el río Jipijapa.

A partir de las calles Bolívar y Villamil (casa antigua Thalía) hasta la calle Macará (casa del Dr. Murillo) está oculto el río debido a la construcción de los mercados municipales, asfalto, viviendas, entre otros. Desde la avenida La Prensa pasado por el baipás siguiendo su cauce en la ciudadela Luis Bustamante, el bario 3 de Julio, ciudadela la Sultana y finalizando en la urbanización La Nueva Villa de Oro, se puede apreciar la maleza que tiene un buen tamaño de altura la cual dificulta la visión y la fluidez del agua, además las agresiones de todo tipo: animales muertos, desechos de construcciones, maleza sin cortar, que desde hace mucho tiempo sufre el río Jipijapa, lo han convertido en un lugar sucio, descuidado, contaminante, deprimente y peligroso para la salud humana, por ende, no ayuda a la afluencia turística. 
En el territorio del cantón Jipijapa se encuentran 9 cuencas hidrográficas (MUÑOZ, 2015) mismas que son las siguientes: Jipijapa, Sangán, Salado, Naranjal, Cantagallo, Buenavista, La Piñas, Ayampe, Salitre, La Pila, El Mono, Membrillal. En el cantón son reducidos los estudios sobre problemas ambientales, es poca la información existente sin embargo es notoria la contaminación de las aguas del río Jipijapa que atraviesa el casco urbano, contaminado por las descargas de aguas negras domiciliarias y basura depositada en la mayor parte de sus tramos. Así mismo se puede evidenciar otro tipo de contaminación de menor escala causada por: las ladrilleras, avícolas, gasolineras, lavadoras de vehículos, lubricadoras, talleres mecánicos, distribuidoras de gas, automotores que efectúan su actividad productiva, sin considerar normas ambientales existentes.

Al respecto de las agresiones, la jipijapense Teresa Quimís señaló que es preocupante y causa decepción que las instituciones y la ciudadanía permanezcan indiferentes ante el estado del río y opinó que debería hacerse causa común para rescatarlo del abandono. En el departamento del ambiente del cabildo se indicó que no existe ningún proyecto con miras a rescatar el río, lo que se ha hecho son dos mingas de limpieza, pero es un trabajo a medias porque se requiere de más personal y maquinarias; Miguel Osejos, docente de Biología de la UNESUM, dijo que han investigado sobre la contaminación del río y hallado echerichia coli y salmonella lligela, provenientes del excremento humano y de chancheras (EL DIARIO, 2011).

Flérida Quimís, técnica del departamento de ambiente de la municipalidad, manifestó que no hay colaboración de los moradores que viven en las riberas del río para mantenerlo limpio, incluso se tiene conocimiento que algunos contratistas de obras botan los desechos de construcción. Miguel Osejos, docente de Biología de la carrera de Medio Ambiente de la UNESUM, expresó que han hecho investigaciones sobre la contaminación del agua del río y los resultados han dado positivos en la existencia de bacterias, además, realizaron un estudio sobre los desechos que se botan y se determinó que causan un gran deterioro del ambiente. Los tramos que están tunelizados son otro gran peligro, por estar convertidos en criaderos de moscas y roedores; Osejos aseguró que estudiantes de la carrera han dado charlas de concienciación a moradores de determinados sectores en las riberas del río, pero no responden, de igual manera han invitado al Municipio para trabajar de manera conjunta pero no hay respuesta (EL DIARIO, 2011).

Así también Calle (2011, pág. 39) Ingeniero en Medio Ambiente de la Universidad Estatal del Sur de Manabí realizó su tesis con el tema "Contaminación del agua del rio Jipijapa por los residuo del proceso de beneficio de café" demostrando los siguientes resultado con el análisis físico químico y bacteriológicos, el agua es putrefacta que alcanza un valor de 6.6 FAU en turbiedad, con un $\mathrm{Ph}$ promedio de 7.86, temperatura promedia de $23.8^{\circ} \mathrm{C}$, con $2450 \mathrm{uS} / \mathrm{cm}$ de conductividad eléctrica y con una cantidad de $1169 \mathrm{mg} / \mathrm{lt}$ de sólidos totales; (CALLE, 2011, pág. 42). Por otra parte los análisis químicos del agua del Rio Jipijapa, reportan que el agua alcanza un valor de $360 \mathrm{mg} / \mathrm{tt}$, de Demanda Química de Oxigeno DQO, con una demanda bioquímica de oxigeno DBO promedio de $55 \mathrm{mg} / \mathrm{lt}$, y el magnesio 
con valor de $55 \mathrm{mg} / \mathrm{lt}$.,también el cloro residual tiene un resultado de 2.9 ya que el promedia del cloro total 0,31mg/; (CALLE, 2011, pág. 43) y los análisis microbiológicos, demuestran presencia de aerobio mesofilos totales con resultado incontable, además presencia de coliformes fecal, coliformes total y salmonella, es decir presencia de bacteria de origen fecales, lo que confirma que el agua del rio está totalmente contaminada.

La problemática es de relevancia local sin embargo para fomentar el turismo del cantón se torna de carácter internacional ya que los turistas extranjeros son los que aportan un porcentaje más elevado en la economía en el ámbito turístico.

Es necesario determinar que el presente trabajo de investigación se elabora sin fines de lucro, más bien pensando en el porvenir del cantón y cuidado de las riquezas naturales. Es muy importante para la ciudad y para las autoridades conocer los problemas que se observan en las riberas del río Jipijapa con necesidades de proyectos de mejoramiento y adecuación para convertirlo en un atractivo turístico y a su vez, aportar al desarrollo económico del cantón. A más de esto se busca tener un ambiente saludable y de buen vivir, así los resultados de esta investigación serán un aporte importante para los departamentos de Higiene y Salubridad, de Ecología y Medio Ambiente de la Municipalidad, que tienen el compromiso de buscar alternativas a los problemas de contaminación ambiental y a el departamento de Turismo para comenzar a dar realce al tema ya que los recursos naturales, culturales y humanos son necesarios para el desarrollo de proyectos turísticos.

La investigación científica presentada busca aportar con ideas para mejorar la apariencia del río Jipijapa y así incrementar la afluencia turística en la ciudad Jipijapa de forma segura sostenible y sustentable, con el apoyo de estudiantes de la carrera de ingeniería en Ecoturismo de la facultad de ciencias económica de la Universidad Estatal del Sur de Manabí demostrando sus capacidades, habilidades y conocimientos adquiridos durante su periodo de formación en el tercer nivel.

El río Jipijapa esta descuidado por las autoridades y maltratado por los habitantes del cantón además pasa desapercibido por muchos visitantes y turistas que viene con frecuencia dada a la poca importancia que se le da además en el Estado actual no se le puede dar una apropiada difusión.

Cabe argumentar que el 10 de agosto del 2017 la ciudad Jipijapa recibió la declaratoria oficial por parte del Ministerio de Cultura y Patrimonio mediante Acuerdo Ministerial № DM-2017-019, además considera que en el cantón existe el interés de las autoridades por conservar la identidad cultural de la ciudad, visible en los inmuebles, conjuntos urbanos y espacios públicos que poseen una arquitectura de valor, con características propias de la región, razón por la cual, la Dirección Regional 4 del Instituto Nacional de Patrimonio Cultural elaboró el "Expediente Técnico para la Declaratoria de la Ciudad De Jipijapa como Patrimonio Cultural Nacional".

Con el objetivo de precautelar y preservar la estructura urbana arquitectónica más antigua de dicho cantón, mediante Oficio Nro. INPC - 
2017-0365-0 de 27 de abril de 2017, la Directora Ejecutiva del Instituto Nacional de Patrimonio Cultural remite al Ministro de Cultura y Patrimonio, el expediente técnico antes referido y las fichas de inventario, solicitando la expedición del Acuerdo Ministerial que declare como bienes del patrimonio cultural nacional a diecisiete (17) inmuebles, un (1) conjunto urbano y dos (2) espacios públicos localizados en el cantón Jipijapa (provincia de Manabí). Que mediante Memorando Nro. MCYP-SPC-17-0231-M de 2 de junio de 2017, la Subsecretaria de Patrimonio Cultural remite a la Coordinación General Jurídica, el "Informe de Viabilidad Técnica para la Declaratoria como Bienes Pertenecientes al Patrimonio Cultural de la Nación a 17 Inmuebles, 1 Conjunto Urbano y 2 Espacios Públicos Localizados en la Ciudad de Jipijapa, Provincia de Manabí", donde se concluye que el proceso cumple con todos los requisitos y criterios necesarios exigidos en la Ley Orgánica de Cultura y su Reglamento General (MINISTERIO DE CULTURA Y PATRIMONIO, 2017)

\section{Marco teórico}

\section{Contaminación}

En el diccionario de definiciones (2017) dice que la contaminación es la introducción de algún tipo de sustancia o energía que atentará contra el normal funcionamiento y equilibrio que ostentaba el medio inicialmente, provocando además un daño casi irreversible, sin embargo la Ley de Gestión Ambiental (2004, pág. 11) afirma que es la presencia en el ambiente de sustancias, elementos, energía o combinación de ellas, en concentraciones y permanencia superiores o inferiores a las establecidas en la legislación vigente, así mismo se refiere a lo que es el Control Ambiental como la vigilancia, inspección y aplicación de medidas para mantener o recuperar características ambientales apropiadas para la conservación y mejoramiento de los seres naturales y sociales, para evitar el daño ambiental ya que es toda pérdida, disminución, detrimento o menoscabo significativo de la condiciones preexistentes en el medio ambiente 0 uno de sus componentes. Afecta al funcionamiento del ecosistema o a la renovabilidad de sus recursos, ocasionando un impacto ambiental, es decir la alteración positiva o negativa del medio ambiente, provocada directa o indirectamente por un proyecto o actividad en un área determinada. Pare ello, es mejor tener precaución, la cual se refiere a la adopción de medidas eficaces para impedir la degradación del medio ambiente.

\section{Preservación de la Naturaleza}

Es el conjunto de políticas, planes, programas, normas y acciones destinadas a asegurar el mantenimiento de las condiciones que hacen posible el desarrollo de los ecosistemas y así lograr la Protección del Medio Ambiente considerando que es el conjunto de políticas, planes, programas, normas y acciones destinadas a prevenir y controlar el deterioro del medio ambiente. Incluye tres aspectos: conservación del medio natural, prevención y control de la contaminación ambiental y manejo sustentable de los 
recursos naturales. La protección ambiental, es tarea conjunta del Estado, la comunidad, las organizaciones no gubernamentales y sector privado todo esto lo estipula la Ley de Gestión Ambiental en su glosario de definiciones.

\section{Contaminación del agua}

La contaminación hídrica se entiende como la acción de introducir algún material en el agua alterando su calidad y su composición química. Según la Organización Mundial de la Salud el agua está contaminada "cuando su composición se haya modificado de modo que no reúna las condiciones necesarias para el uso, al que se le hubiera destinado en su estado natural' (INSPIRACTION, 2018). El agua que procede de ríos, lagos y quebradas es objeto de una severa contaminación, muchas veces producto de las actividades del hombre. También indica cuales son los principales contaminantes del agua, mencionando a los agentes patógenos: algunas bacterias, virus y parásitos, provenientes de desechos orgánicos, entran en contacto con el agua; los desechos que requieren oxígeno: algunos desperdicios pueden ser descompuestos por bacterias que usan oxígeno para biodegradarlos.

Cuando existen grandes poblaciones de estas bacterias pueden llegar a agotar el oxígeno del agua, matando toda la vida acuática, las sustancias químicas inorgánicas como los ácidos y los compuestos de metales tóxicos envenenan el agua, las sustancias químicas orgánicas como el petróleo, el plástico, los plaguicidas y los detergentes amenazan la vida en el agua, los nutrientes vegetales pueden ocasionar el crecimiento excesivo de plantas acuáticas. Estas mueren y se descomponen agotando el oxígeno del agua y provocando la muerte de varias especies marinas. La mayor fuente de contaminación proviene de los sedimentos o materia suspendida que enturbian el agua concluyendo que el aumento de la temperatura disminuye la cantidad de oxígeno en el agua, vulnerando la supervivencia de los organismos acuáticos.

\section{Turismo}

La Organización Mundial del Turismo (OMT, 2017) dice que es un fenómeno social, cultural y económico relacionado con el movimiento de las personas a lugares que se encuentran fuera de su lugar de residencia habitual por motivos personales 0 de negocios/profesionales. Estas personas se denominan visitantes (que pueden ser turistas o excursionistas; residentes o no residentes) y el turismo tiene que ver con sus actividades, de las cuales algunas implican un gasto turístico.

Según el Art. 2 de la Ley de Turismo (MINTUR, 2011), es el ejercicio de todas las actividades asociadas con el desplazamiento de personas hacia lugares distintos al de su residencia habitual; sin ánimo de radicarse permanentemente en ellos. siguientes:

En el Art. 3 dice que son principios de la actividad turística, los 
a) La iniciativa privada como pilar fundamental del sector; con su contribución mediante la inversión directa, la generación de empleo y promoción nacional e internacional;

b) La participación de los gobiernos provincial y cantonal para impulsar y apoyar el desarrollo turístico, dentro del marco de la descentralización;

c) El fomento de la infraestructura nacional y el mejoramiento de los servicios públicos básicos para garantizar la adecuada satisfacción de los turistas;

d) La conservación permanente de los recursos naturales y culturales del país; y,

e) La iniciativa y participación comunitaria indígena, campesina, montubia o afro ecuatoriana, con su cultura y tradiciones preservando su identidad, protegiendo su ecosistema y participando en la prestación de servicios turísticos, en los términos previstos en esta Ley y sus reglamentos.

\section{Demanda turística}

El concepto de demanda está íntimamente relacionado con el proceso de toma de decisiones que los individuos realizan constantemente en el proceso de planificación de sus actividades de ocio y, por lo tanto, su determinación depende de numerosos factores no sólo económicos, sino también psicológicos, sociológicos, físicos y éticos es lo que determina la Organización Mundial del Turismo mediante una investigación realizada para elaborar el libro Introducción al Turismo (Sancho, 1998) La definición de demanda turística variará según los intereses que muevan al investigador. Así, un economista se centrará en la demanda desde el punto de vista del consumo, un psicólogo se interesará más por el comportamiento y las motivaciones de dicha demanda, etc. Gómez y López ofrecen una definición con connotaciones geográficas: "El número total de personas que viajan o desean viajar, para disfrutar de facilidades turísticas y de servicios en lugares distintos al lugar de trabajo y de residencia habitual" (2002, pág. 16).

\section{Medio ambiente y desarrollo sostenible}

La Organización de Naciones Unidas dice que el desarrollo sostenible puede ser definido como "un desarrollo que satisfaga las necesidades del presente sin poner en peligro la capacidad de las generaciones futuras para atender sus propias necesidades" (CINU, 2016). Esta definición fue empleada por primera vez en 1987 en la Comisión Mundial del Medio Ambiente de la ONU, creada en 1983. Sin embargo, el tema del medio ambiente tiene antecedentes más lejanos. En este sentido, las Naciones Unidas han sido pioneras al tratar el tema, enfocándose inicialmente en el estudio y la utilización de los recursos naturales y en la lucha porque los países, en especial aquellos en desarrollo, ejercieran control de sus propios recursos naturales. 


\section{Sensibilización del turista por aspectos ambientales}

La Organización Mundial del Turismo (OMT) ha reconocido una sensibilización del turista por aspectos ambientales. El factor va más allá de la diversificación motivacional, es una valoración incluida dentro de las grandes tendencias del mundo actual. No solamente hay un conjunto de tipos de turismo específicos de base ambiental, sino que cualquier actividad turística tiene que considerar su aspecto ambiental. Desde esta perspectiva se puede distinguir cuatro maneras distintas de intervenir el ambiente en la oferta turística.

1. Como motivación exclusiva, lo que ha dado el ecoturismo o turismo de la naturaleza.

2. Teniendo en cuenta el ambiente, como principal factor, pero no único. Ejemplo de esto es el turismo rural, incluyendo el concepto ambiental desde la antropología.

3. Cuando el aspecto ambiental tiene el carácter complementario. Aquí, el entorno se convierte en un espectáculo, con una duración y un entorno limitado (parques temáticos, delfinarios, acuarios), etc.

4. Cuando el ambiente entraría formando parte, de algún modo, de los productos y servicios concretos. Hoteles con energía alternativa, restaurantes con productos ecológicos, transportes no contaminantes, etc.

\section{La educación ambiental en el turismo}

La educación ambiental adquirió auge a partir de 1970 cuando la degradación ambiental comenzó a considerarse como un problema social. De esta forma desde el Coloquio Internacional sobre Educación relativa a Medio ambiente (BELGRADO 1975) y la Conferencia Internacional de Medio Ambiente y Sociedad (TESALÓNICA, 1997) hasta la actualidad, se ha avanzado desde el punto de vista teórico y práctico en el campo de la educación ambiental.

El desafío de la educación ambiental es promover una nueva relación de la sociedad humana con su entorno, a fin de procurar a las generaciones actuales y futuras un desarrollo personal y colectivo más justo, equitativo y sostenible. Si se considera el pensamiento de Guattari (1992 apud LEME, 2009) sobre las tres ecologías, una es la ecología mental (para conmigo), otra la ecología social (para con los demás) y finalmente la ecología ambiental (para con la naturaleza) (CLADES, 2017).

Estos tres tipos están interrelacionados de forma que no se puede mejorar uno y posteriormente otro; sino que debe realizarse una acción sistémica y conjunta contemplando desafíos profundos como la subjetividad, la relación del hombre consigo mismo y la alteridad en la relación con los demás. Se puede afirmar que la educación ambiental es por sobre todas las cosas una educación para la acción, desde una aproximación global e interdisciplinar, facilitando así un mejor conocimiento de los procesos ecológicos, económicos, sociales y culturales. 


\section{Descripción del área geográfica}

Según investigaciones realizadas por Carvache, Carvache y Torres (2017) en su artículo científico expone que Ecuador en un país con importantes atractivos turísticos cuyas políticas públicas están encaminadas a mejorar su oferta turística. Los principales mercados emisores de donde provienen los turistas internacionales en el año 2015, los conformaron Colombia, Estados Unidos y Perú. Según datos del MINTUR (2016) a Ecuador en el año 2015 llegaron 1.543,165 turistas internacionales y en el año 2014 llegaron 1'557.006 de turistas internacionales.

En las exportaciones no petroleras, el turismo ocupa el tercer lugar luego del banano y camarón. De acuerdo con el MINTUR (2016) durante el año 2015 el ingreso de divisas por concepto de viajes y transporte de pasajeros alcanzó la suma de 1.557,4 millones de dólares, mientras en el año 2014 recibió 1.487,20 millones de dólares, observando un incremento del $4,7 \%$ con respecto al año anterior, obteniendo un saldo de 532,9 millones en la balanza turística del año 2015.

La provincia de Manabí limita al norte con la provincia de Esmeraldas, al sur con las provincias de Santa Elena y Guayas, al este con las provincias de Guayas, Los Ríos y Santo Domingo de los Tsàchilas, y al oeste con el Océano Pacifico. Por tratarse de una provincia costera, Manabí tiene escasas elevaciones que no sobrepasan los 500 metros, sobre el nivel del mar. De la provincia del Guayas viene la cordillera del Chongón - Colonche y toma los nombres de cerros de Paján y luego de Puca. Esta cordillera es la columna vertebral de la región (GOBIERNO PROVINCIAL DE MANABÍ, 2016)

Hidrografía: El cruce de la cordillera de Chongón-Colonche y la Cordillera de Balzar obstaculiza la existencia de ríos de caudal que desemboquen en el Océano Pacífico, con excepción cuantos que son importantes en invierno como el río Chone y río Portoviejo que son los únicos con cauce profundo; esto determina que ciertas zonas de la provincia estén predispuestas a inundaciones en las temporadas invernales de mayor precipitación. El río Chone es el más importante por su caudal, nace en las faldas occidentales de la cordillera de Balzar y desemboca en Bahía de Caráquez. Sus principales afluentes son: por la margen derecha los ríos Mosquito, Garrapata, San Lorenzo y por la margen izquierda: el Tosagua, con sus afluentes: Canuto y Calceta.

La cuenca que riegan estos ríos es una de las más importantes y fértiles de la provincia. El río Portoviejo nace en las montañas de Paján y Puca y desemboca en la bahía de Charapotó en un sitio turístico conocido como "La Boca". El río Canoa nace en las montañas de ese nombre y recibe las aguas del Tabu chilla y el Muchacho. Entre Canoa y San Vicente desemboca el río Briceño que es de poco caudal. Finalmente, el río Jama que nace en los cerros de su nombre y su principal tributario, el río Mariano. (ECURED, 2016)

En el PDOT de Jipijapa (MUÑOZ, 2015) afirma que se localiza en el extremo sur occidental de la Provincia de Manabí, A 403 Km., de Quito 
capital del Ecuador. Sus límites son: El cantón Jipijapa, está limitado al norte por los cantones Montecristi, Portoviejo y Santa Ana, al Sur por la provincia de Santa Elena y Puerto López, al este por los cantones Paján y 24 de Mayo; y, al oeste por el Océano Pacifico.

El cantón está ubicado al sur de la provincia de Manabí, entre los 01 grados 10 minutos y 01 grados 47 minutos de latitud sur y entre los 80 grados 25 minutos y 80 grados 52 minutos de longitud oeste (Imagens 1, 2 e 3). Tradicionalmente se conoce a Jipijapa como la Sultana del Café, por haber sido el primer cantón productor de café en el Ecuador.

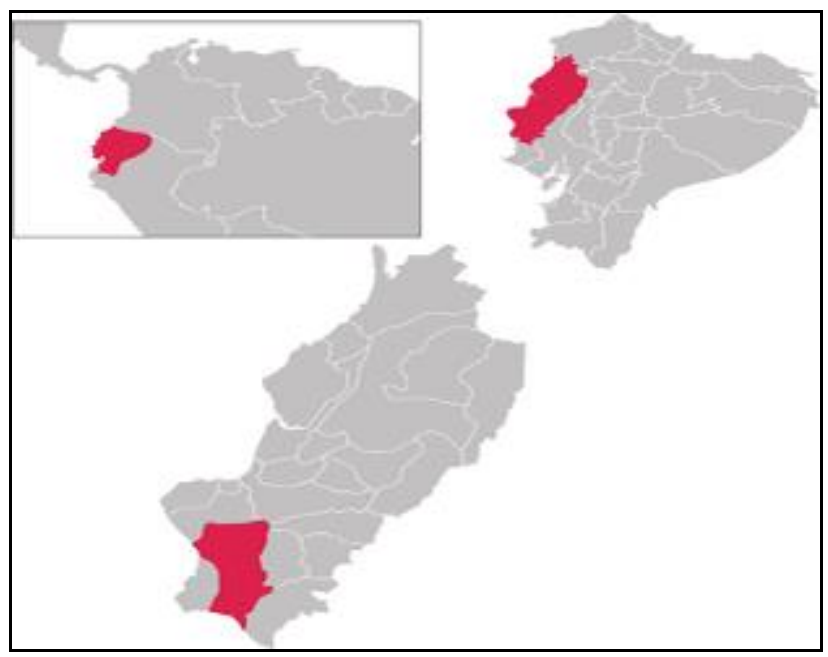

Imagen 1: Mapa regional Cantón Jipijapa. Fuente: GAD Manabí (2016).

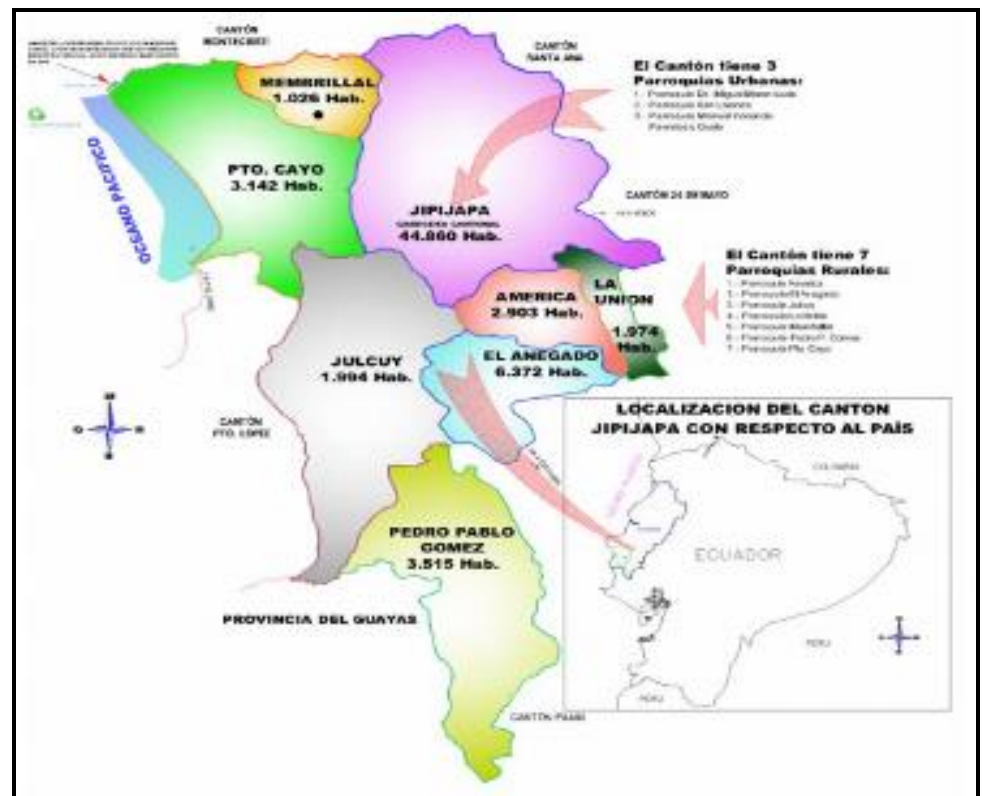

Imagen 2: Cantones de Manabí. Fuente: GAD Manabí (2016)

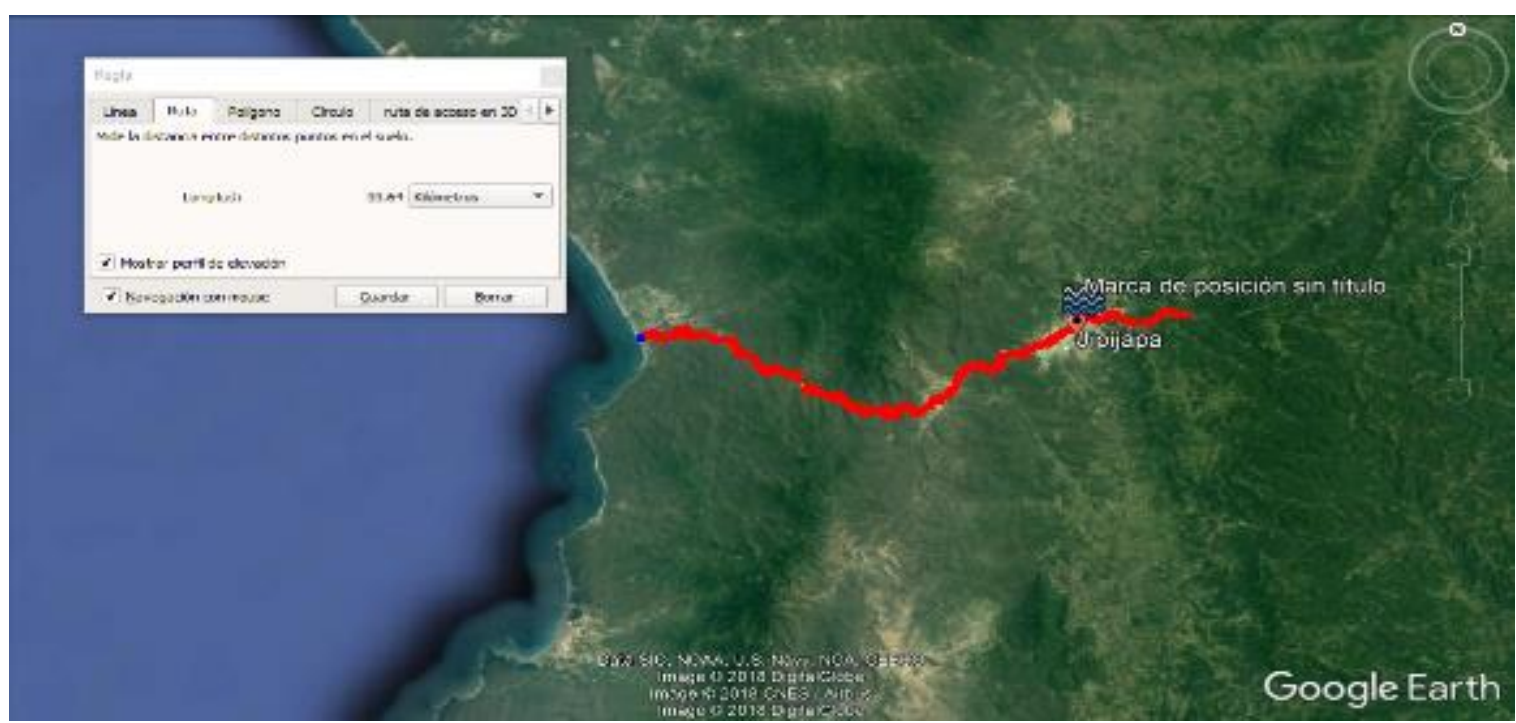

Imagen 3: Posicionamiento territorial del río Jipijapa.

Fuente: Google Earth. 
En relación a su topografía, existe un macizo montañoso aislado e irregular, que se desarrolla entre Jipijapa y Manta, rodeado al norte y oeste por el Océano Pacifico, al sur por el valle de Jipijapa y al este por el río Portoviejo. En el valle termina la cordillera de Colonche y las montañas costaneras que siguen hacia Bahía de Caráquez. No se presentan cadenas largas, más bien son grupos macizos irregulares.

El clima de Jipijapa es tropical seco, con una temperatura media de 24 grados centígrados y un promedio de lluvia anual de 1.280 milímetros cúbicos. En la ensenada de Cayo desemboca el Río Seco de Jipijapa, además existen los ríos Cantagallo, Salitre, Naranjal, Salado y Piñas. Su caudal es pequeño. Su nombre se debe a que en el siglo XV estuvo habitada por la tribu indígena Xipixapa, aunque se cree que también los Mayas se extendieron por esta región. También se dice que Jipijapa tuvo influencia de las culturas Valdivia, Machalilla, Chorrera, Manteño, Huancavilca y restos de esta cultura se conservan en el parque nacional Machalilla.

Según información obtenida de Muñoz (2015) sus principales atractivos turísticos son: Los pozos de Andil, Choconchá, Joa, Chade, Flor del Salto, Montaña Chocotete, Playas de Puerto Cayo y Cantagallo, Bosques El Chorrillo, Olina, Santo sin Cabeza, Cascadas El Chorrillo, Bajo Grande, Agua Dulce, San Antonio, Maryland, Margarita, Andrecillo, Valle el Ramito, Cuevas de Manchuria, Petroglifos Santo sin Cabeza, Iglesia San Lorenzo, Museo Municipal, Parque Central.

\section{Metodología}

Para la realización del presente trabajo de investigación científica se realizó el siguiente procedimiento:

-Análisis de la demanda;

-Análisis de examen directo, cultivo bacteriano y cultivo micológico del agua.

\section{Análisis de la demanda}

Para la realización del análisis de la demanda se utilizaron datos de un proyecto de investigación de la Universidad Estatal del Sur de Manabí de la Facultad de Ciencias Económicas Carrera de Ingeniería en Ecoturismo siendo la autora la Ingeniera Nery Sánchez con el tema "Determinación de la demanda turística del cantón Jipijapa como aporte al desarrollo del turismo" en el año 2013, tema donde se considera la demanda del cantón Jipijapa.

\section{Universo y Muestra}

Se utilizó la misma muestra población de la investigación antes mencionado, es decir, 390 turistas, con el que se calculó la muestra, estableciendo un total de 194 encuestas a realizarse. 


\section{FORMULA}

$$
n=\frac{z^{2} N P Q}{e^{2} N+z^{2} P Q}
$$

Donde:

$$
\begin{aligned}
& \mathrm{n}=\text { Tamaño de la muestra } \\
& \mathrm{Z}=\text { Margen de confiabilidad, } \\
& \mathrm{e}=\text { Error admisible } \\
& \mathrm{N}=\text { Tamaño de la población } \\
& \mathrm{n}=? \\
& \mathrm{Z}=1,96 \\
& \mathrm{P}=0,5 \\
& \mathrm{Q}=0,5 \\
& \mathrm{e}=5 \% \\
& \mathrm{~N}=
\end{aligned}
$$

NIVEL DE CONF.

ERROR

VALOR Z

\section{DESARROLLO}

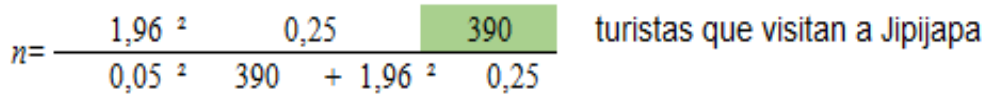

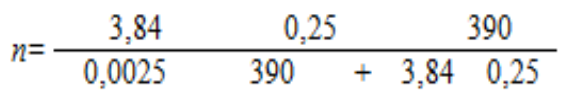$$
n=\frac{375}{0,98+0,96}
$$

$$
\begin{aligned}
& n=\frac{375}{1,94} \\
& n=\quad \mathbf{1 9 4} \text { Turistas a encuestar }
\end{aligned}
$$

$$
\begin{array}{r}
95 \% \\
5 \% \\
1,96
\end{array}
$$

Análisis de examen directo, cultivo bacteriano y cultivo micológico del agua

Después de haber indagado en los trabajos de investigación sobre el río de Jipijapa que se pudo encontrar se realizaron investigaciones para actualizar los datos obtenidos; se realizaron varios análisis del agua para la cual se tomaron muestras de diferentes tramos:

1.Ciudadela Luis Bustamante

2.En las calles 10 de Agosto e Imbabura, la ciudadela 3 de Mayo

3.En el sitio Choconchá

\section{Materiales y métodos}

\section{Análisis de la demanda}

\section{Encuesta realizada a los turistas y habitantes de Jipijapa}

El presente trabajo de investigación tiene como objetivo conocer la importancia que se le da al río Jipijapa y las posibilidades de aceptación en caso se implementarán actividades turísticas para aportar al desarrollo económico del cantón. 
¿Conoce usted el rio jipijapa? S

No

1. ¿Cree usted que es necesario tomar medidas de prevención para disminuir la contaminación del río Jipijapa? Sí No ¿Cuáles?

2. ¿Si el río Jipijapa tuviese una mejor apariencia con qué frecuencia lo visitaría? Cada semana cada 15 días cada mes

3. ¿Está dispuesto a realizar actividades turísticas en el rio jipijapa?

Sí No

4. ¿Qué tipo de actividades turísticas le gustaría que se implementara en el tramo del río Jipijapa? Sendero para ciclista Sendero para trotar

Pesca deportiva ; Balneario , Outro , ¿Cuál?

5. ¿Cree usted que es importante que exista un proyecto sobre el cuidado y preservación del río Jipijapa? Sí No

6. ¿Si se implementaran estas actividades cuál cree usted que sería el grado de aportación al desarrollo económico del Cantón?

Bajo Medio Alto

\section{Resultados}

Se realizaron 194 encuestas de forma aleatoria simple a 100 habitantes y 94 turistas en el centro de la ciudad y en el área del terminal terrestre de las cuales se obtuvieron las siguientes respuestas.

1.¿Conoce usted el río Jipijapa?

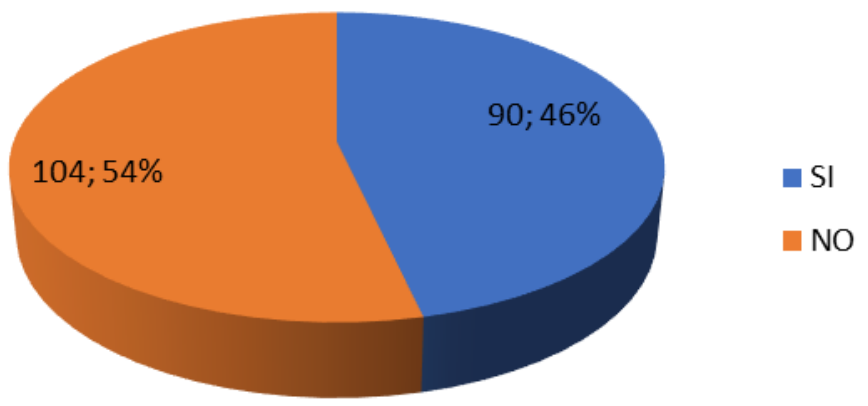

En esta pregunta 104 personas dijeron que no conocen el río Jipijapa que equivale al 54\% y representan a los turistas encontrados en la ciudad más 10 habitantes; 90 dijeron que si lo conocen que equivale al $46 \%$ y son los habitantes de la ciudad. 
2. ¿Cree usted que es necesario tomar medidas de prevención para disminuir la contaminación del río Jipijapa?

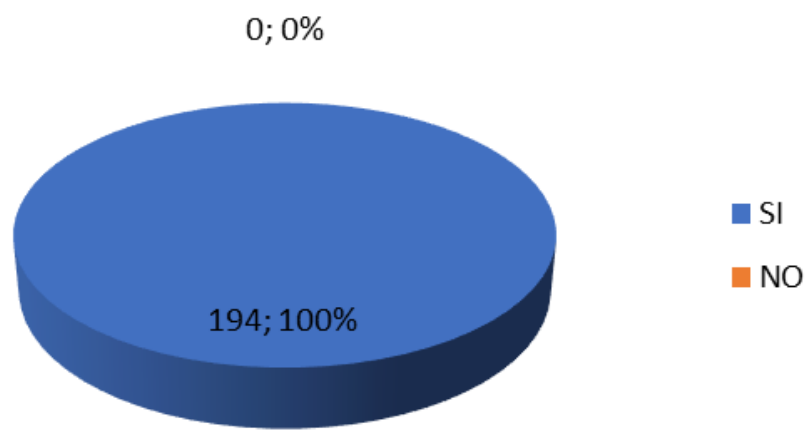

Todas las personas encuestadas dijeron que si es necesario tomar medidas de prevención para disminuir la contaminación del río Jipijapa y dieron varias ideas como: desbroce de maleza rótulos con prevención de no botar basura, cobro de multas para las personas que botan basura en las riberas del río, mingas, capacitaciones de concientización, entre otros. visitaría?

3 ¿Si el río Jipijapa tuviese una mejor apariencia con qué frecuencia lo

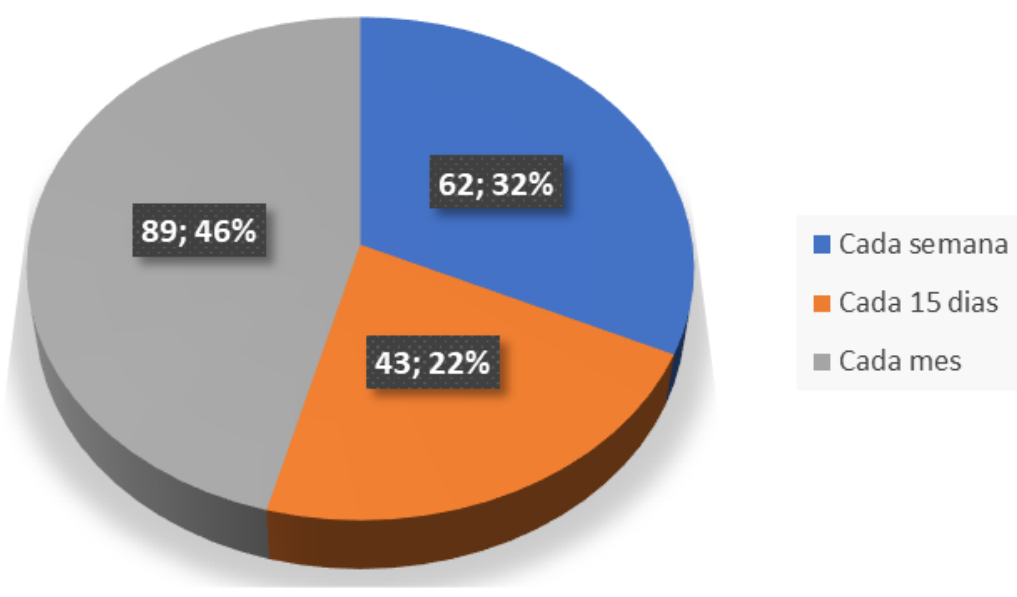

Con el resultado se puede concluir que si el rio tuviese una mejor apariencia fuera visitada con una frecuencia considerable ya que 89 personas dijeron que lo visitarían una vez al mes el cual equivale al el $46 \%$, 62 personas dijeron que lo harían cada 15 días el cual representa al $32 \%$ y 43 cada semana es decir el $22 \%$. 
4.¿Está dispuesto a realizar actividades turísticas en el rio jipijapa?

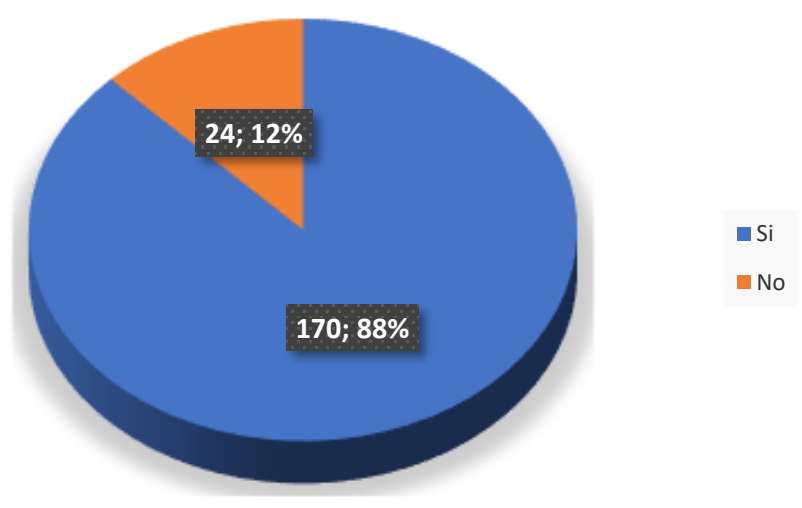

En esta grafica se puede observar que el $88 \%$ de personas encuestadas están dispuestas a realizar actividades turísticas en el rio Jipijapa y solo el $12 \%$ no lo harían.

5.¿Qué tipo de actividades turísticas le gustaría que se implementara en el tramo del río Jipijapa?

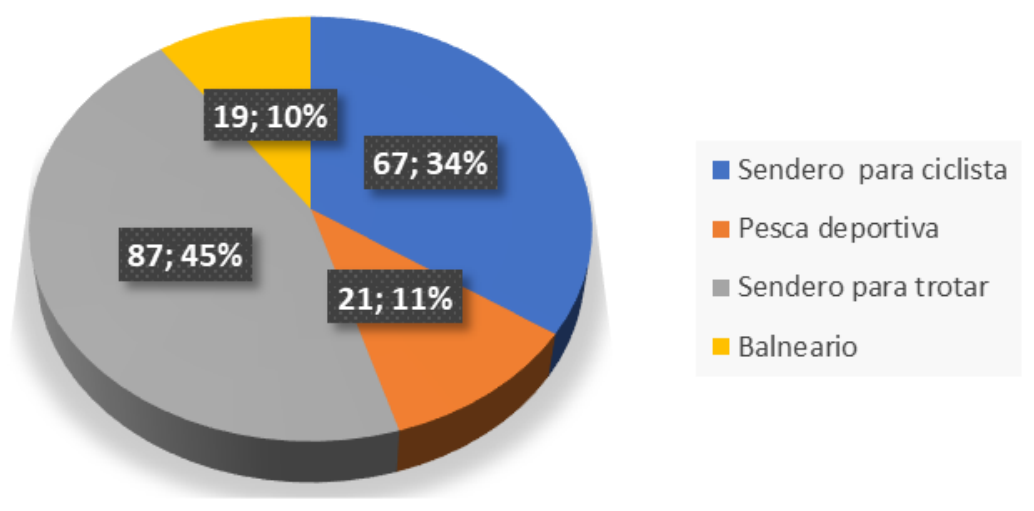

Por medio de esta respuesta se puede concluir que el $67 \%$ de personas encuestadas le gustaría que se implementara un sendero para ciclistas, al $21 \%$ les gozarían practicar pesca deportiva, el $19 \%$ que se adecuara para disfrutar de un balneario, mientras que la mayoría fue el $87 \%$ y dijeron que les gustaría se construyera un sendero para trotar. 
6. ¿Cree Ud. que es importante que exista un proyecto sobre el cuidado y preservación del río Jipijapa?

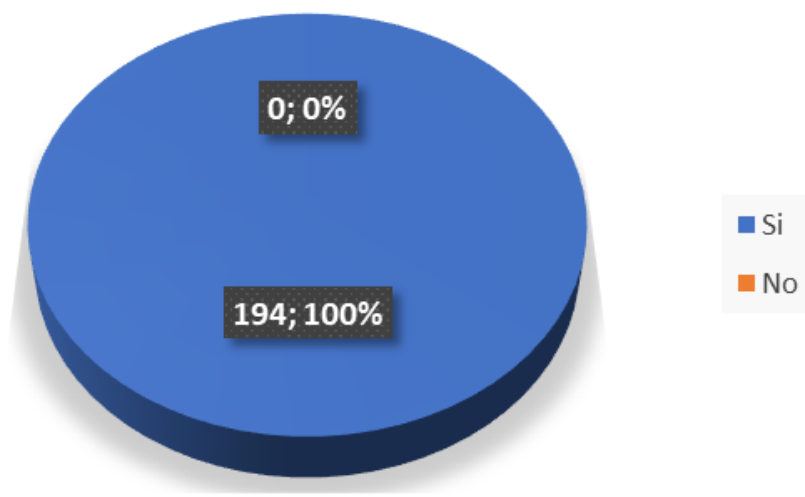

Las personas encuestadas están totalmente de acuerdo que es importante que exista un proyecto sobre el cuidado y preservación del río Jipijapa de forma urgente.

7. ¿Si se implementara estas actividades cuál cree usted que sería el grado de aportación al desarrollo económico del Cantón?

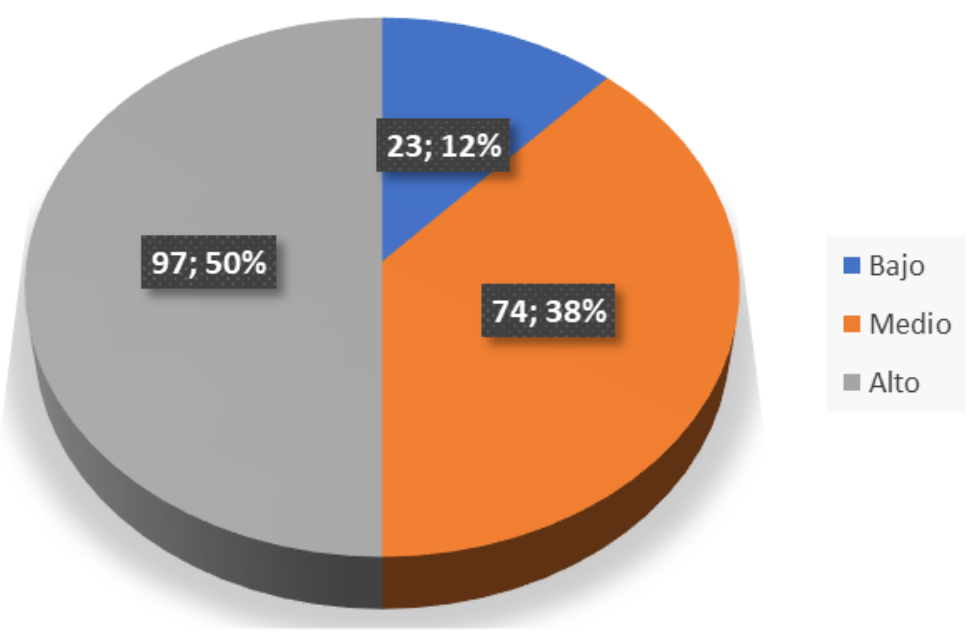

En esta pregunta realizada se estima que el nivel de aportación al desarrollo económico de del cantón en caso de que se implementara varias actividades turísticas seria en un $12 \%$ en nivel bajo, en un $38 \%$ en nivel medio y en un $50 \%$ en nivel alto esto es en cuanto a las opiniones de los encuestados.

\section{Análisis de examen directo, cultivo bacteriano y cultivo micológico del agua}

Se realizaron los análisis de examen directo, cultivo bacteriano y cultivo micológico por la Dra. Rocío Narváez de Martínez, Patóloga Clínica con registro profesional del ministerio de salud pública libro 1"U” folio 4 
número 11 del laboratorio clínico afiliado a Ecuasanitas con fecha 9 de junio del 2016 obteniendo los siguientes resultados:

En la muestra \#1 en el examen directo tiene un aspecto ligeramente turbio, el ph de 6.5, su densidad es decir la cantidad de minerales que contiene el agua es de 1020, los sedimentos que se encontraron son diatomeas (parásitos) y giardina lamblia (quistes y parásitos); en el Cultivo Bacteriano se encontraron bacilos gram negativos identificación del germen escherichia coli y en el Cultivo Micológico se detectaron el agar nickerson's en el cultivo de 72 horas sin crecimiento, y el agar saboureaud en el cultivo de 10 días sin crecimiento; estos mismos datos se detectaron en la muestra tomada en las calles 10 de Agosto e Imbabura

En la muestra \#2 en el examen directo tiene un aspecto claro, el ph de 7, su densidad es decir la cantidad de minerales que contiene el agua es de 1005, no se encontraron sedimentos; en el Cultivo Bacteriano de 24 horas no se encontraron bacterias y en el Cultivo Micológico se detectaron el agar nickerson's en el cultivo de 72 horas sin crecimiento, y el agar saboureaud en el cultivo de 10 días sin crecimiento.

En la muestra \#3 en el examen directo tiene un aspecto claro, el ph de 9 , su densidad es decir la cantidad de minerales que contiene el agua es de 1005, no se encontraron sedimentos; en el Cultivo Bacteriano de 24 horas no se encontraron bacterias y en el Cultivo Micológico se detectaron el agar nickerson's en el cultivo de 72 horas sin crecimiento, y el agar saboureaud en el cultivo de 10 días sin crecimiento.

Haciendo comparación con los resultados realizado por el Ing. Gonzalo Pionce Calle en el 2010 se puede concluir que el agua del río Jipijapa sigue estando contaminada por la bacteria escherichia coli sin embargo esto es solo en el tramo del centro hasta la ciudadela Luis Bustamante mientras que en los tramos alejados del centro de la ciudad están libres de esta bacteria no obstante tienen la presencia de agar nickerson's que es adicionado como agentes solidificantes y agar saboureaud que se utiliza para el aislamiento y el cultivo de hongos.

\section{Conclusiones}

- Cabe destacar que en el cantón Jipijapa no se ha dado la iniciativa por parte de empresas públicas ni privadas de realizar actividades para fomentar la oferta y demanda turística del mismo.

- Con el análisis bacteriológico realizado se puede decir que el agua del río Jipijapa está contaminado, en especial en la zona del centro de la ciudad; sin embargo, en las partes extremas de su cauce están menos contaminada, ahí se podría impulsar la pesca.

- Mediante campañas de concientización se logrará disminuir la contaminación del río Jipijapa para que sus aguas no sean perjudiciales para ningún ser vivo y se pueda implementar actividades turísticas tal como balneario, senderismo y ciclismo. 
- Motivar a las autoridades competentes y a los habitantes de la ciudad para rescatar los recursos naturales a través de proyectos ejecutables, mismos que influirán en el fomento del turismo y a su vez la economía del cantón.

\section{Referencias}

CALLE, A. Contaminación del agua del río Jipijapa por los residuos del proceso de beneficio de café. Jipijapa: Universidad Estatal del Sur de Manabí, 2011.

CARVACHE, M.; CARVACHE, W.; TORRES, M. Análisis de satisfacción La gastronomía de Samborondón - Ecuador. SCIELO, v.5, 2017.

CINU. Medio ambiente y desarrollo sostenible. Obtenido de http://www.cinu.mx/temas/medio-ambiente/medio-ambiente-y-desarrollo-so/, (09 de junio de 2016).

CLADES. Red de ecologia social. Obtenido de http://ecologiasocial.com/red-de-ecologia-social/, (22 de marzo de 2017).

DEFINICIÓN ABC. Definición de Contaminación. Obtenido de https://www.definicionabc.com/medio-ambiente/contaminacion. php, (03 de julio de 2017).

ECURED. Provincia de Manabí. Obtenido de https://www.ecured.cu/Provincia de Manab\%C3\%AD,(30 de julio de 2016).

EL DIARIO. EI río Jipijapa se torna peligroso para la salud. Obtenido de http://www.eldiario.ec/noticias-manabi-ecuador/212621-el-rio-jipijapa-se-

torna-peligroso-para-la-salud/, (03 de diciembre de 2011).

EL DIARIO. Preocupa el estado del río Jipijapa. Obtenido de http://www.eldiario.ec/noticias-manabi-ecuador/212706-preocupa-el-estadodel-rio-jipijapa/, (04 de diciembre de 2011).

GETAMAP. (11 de julio de 2017). Río Jipijapa / Provincia de Manabi. Obtenido de http://es.getamap.net/mapas/ecuador/manabi/ jipijapa rio/

GOBIERNO PROVINCIAL DE MANABÍ. Datos Geográficos. Obtenido de http://www.manabi.gob.ec/datos-manabi/datos-geograficos, $(27$ de mayo de 2016).

GÓMEZ, B., LÓPEZ, F. Regionalización turística del mundo. Barcelona: Ediciones Universitat de Barcelona, 2002.

HONORABLE CONGRESO NACIONAL. (2004). Ley de Gestión Ambiental. Quito: Registro Oficial.

INSPIRACTION. Contaminación del agua. Obtenido de https://www.inspiraction.org/cambio-climatico/contaminacion/ contaminaciondel-agua, (23 de enero de 2018).

MINISTERIO DE CULTURA Y PATRIMONIO. (2017). Declaración de bienes de patrimonio. Quito: Registro Oficial.

MINTUR. Ley de Turismo. Quito: Registro Oficial. (22 de julio de 2011). 
MUÑOZ, P. PDOT GAD de Jipijapa. Quito: Secretaría Nacional de Planificación y Desarrollo. (12 de abril de 2015).

OMT. Entender el turismo: Glosario Básico. Obtenido de http://media.unwto.org/es/content/entender-el-turismo-glosario-basico (25 de noviembre de 2017).

$\mathrm{SANCHO}, \mathrm{A}$. Introducción al turismo. Ginebra: Organización Mundial del Turismo, 1998.

Ingrid Jahaira Sánchez Guaranda: Universidad Estatal del Sur de Manabí, Jipijapa, Manabí, Ecuador.

E-mail: injasagu21@gmail.com

Miguel Ángel Parrales Oviedo: Universidad Estatal del Sur de Manabí, Jipijapa, Manabí, Ecuador.

E-mail: parrales25@hotmail.com

Luis Manuel Toala Baque: Universidad Estatal del Sur de Manabí, Jipijapa, Manabí, Ecuador.

E-mail: merricluis@hotmail.com

Shyla Orlando Narváez: Universidad Estatal del Sur de Manabí, Jipijapa, Manabí, Ecuador.

E-mail: shyla.orlando@unesum.edu.ec

Data de submissão: 04 de agosto de 2018

Data de recebimento de correções: 08 de março de 2019

Data do aceite: 08 de março de 2019

Avaliado anonimamente 